Mal J Nutr 25(2): 227-236, 2019

\title{
Plain water and beverage consumption patterns among university students in Puncak Alam, Malaysia
}

\author{
Nur Islami Mohd Fahmi Teng ${ }^{1 *}$, Norsham Juliana Nordin ${ }^{2}$ \& Aisyah Suraya \\ Muhammad Shah ${ }^{1}$ \\ ${ }^{1}$ Faculty of Health Sciences, Universiti Teknologi MARA, Cawangan Selangor, \\ Kampus Puncak Alam, Selangor; ${ }^{2}$ Faculty of Medicine and Health Sciences, Universiti \\ Sains Islam Malaysia, Kuala Lumpur
}

\begin{abstract}
Introduction: Data on water and sugar sweetened beverages (SSB) intake among young adults in Malaysia is sparse. This study aimed at measuring the intake of plain water and SSB among undergraduate students in a Malaysian university and examine its association with body mass index (BMI). Methods: A total of 376 undergraduate students aged 18-30 years were recruited. A selfadministered questionnaire was used to determine the SSB consumption pattern. The questionnaire consisted of five sections that included the background of the participants, knowledge about SSB, SSB preferences, frequency and portion size. Results: $23.9 \%$ of subjects in this study were overweight. Almost all of the subjects took outside food $(93.1 \%)$ and drink $(74.2 \%)$. The highest daily consumption was plain water $(92.3 \%)$, with a majority drinking more than two cups at each intake. Caffeinated drinks (coffee or tea) were the most popular SSB among the students (18.4\%). Most students (79.7\%) did not consume SSB on a daily basis. A significant association was found between the proportion of plain water consumption and BMI $(p<0.05)$. Those who were overweight consumed a greater amount of plain water as compared to those underweight. Conclusion: Our findings of low plain water intake among the underweight may be used to tailor intervention efforts to increase its intake and reduce that of SSB, especially among underweight young adults.
\end{abstract}

Keywords: Sugar sweetened beverages, SSB, plain water, obesity, undergraduate students

\section{INTRODUCTION}

The prevalence of obesity has increased drastically to epidemic proportions in Malaysia. Based on a systematic analysis for the Global Burden of Disease Study (2013), $44.2 \%$ of Malaysian adults have been found to be overweight or obese (Ng et al., 2014). Similar trends have been seen among Malaysian children and adolescents.
These trends could lead to serious health complications in adulthood. Various public health co-morbidities are associated with overweight and obesity, including hypertension, cardiovascular disease, diabetes, depression and multiple type of cancers. Generally, obesity arises from an imbalance of energy homeostasis with the complex interaction between genetic, metabolic,

\footnotetext{
*Corresponding author: Dr Nur Islami Mohd Fahmi Teng

Faculty of Health Sciences, Universiti Teknologi MARA, Cawangan Selangor, Kampus Puncak Alam, 42300 Puncak Alam, Malaysia

Tel: (6)03-32584540; Fax: (6)(03)32584599; E-mail: nurislami@uitm.edu.my

doi: https://doi.org/10.31246/mjn-2018-0128
} 
cultural, environmental, socioeconomic, and behavioural factors (Heitmann et al., 2012). Recent highlights from the Prospective Urban Rural Epidemiology (PURE) study showed that the intake of carbohydrates is high among Malaysians (Dehghan et al., 2017). National survey data has indicated that the consumption of carbohydrates in the form of added sugars has also increased (Amarra, Khor \& Chan, 2016; Dehghan et al., 2017).

Multiple studies have reported that current estimates of added sugar intake among Malaysian children and adults range from $9.0 \%$ to $28.4 \%$, with the highest intake found among adolescents (Amarra et al., 2016). The reported intake is worrying, as it exceeds World Health Organization (WHO) (2015) recommendations which state that added sugar must not exceed $10 \%$ of the total intake of energy. This WHO guideline also recommended to further reduce the intake of free sugars to below $5 \%$ of total energy, if conditions warrant this. This recommendation translates into 25 grams of added sugar or approximately six teaspoons of sugar per day for a $2000 \mathrm{kcal}$ diet. Fructose and non-fructose-rich corn syrups, cane and sucrose, honey and other edible sugar are common types of sugar added to food or beverages.

In the United States, soft drinks are the leading source of added sugar, each serving of which is a high glycaemic load that increases the risk of type 2 diabetes mellitus (T2DM) (Hu \& Malik 2010). However, in Malaysia, the Malaysian Adult Nutrition Survey (MANS) 2003 has pointed out that intake of sweetened beverages such as coffee, teh tarik, and chocolate beverages are the highest contributors to the consumption of added sugar in the daily dietary intake of Malaysian adults' (Norimah et al., 2008).

Water consumption is important for adequate hydration, body function and health. Increased water consumption, specifically plain water, is used as a key message in many weight reduction programmes (Muckelbauer et al., 2013). The Malaysian Dietary Guidelines has recommended drinking 6-8 glasses of plain water daily (NCCFN, 2010). Studies have reported that substituting SSB with plain water plays a significant role in reducing energy intake, and thus can aid in weight management and diabetes prevention (Muckelbauer et al., 2013). As Malaysian's prevalence of T2DM in 2015 (17.5\%) has doubled since 1996, in parallel with obesity, it has become important to identify the extent of SSB intake in the population (Cheah et al., 2018).

This study specifically aimed to determine plain water and SSB intake, and their association with body mass index (BMI), among university undergraduate students in an urban area in Malaysia.

\section{MATERIALS AND METHODS}

\section{Participants}

Undergraduate students at the Puncak Alam campus of Universiti Teknologi MARA, were invited to participate in this cross-sectional study. We advertised the study by using flyers and also approached students at the common areas of the university such as library, student lounge and cafeteria. As there were approximately 16000 registered students, we estimated that a sample size of 376 was needed by using the Raosoft Calculator Software $195 \%$ of confidence level with a $5 \%$ margin error). The participants were required to be free from diet-related disease, mental disorder and physical disabilities. Those who met the study criteria were recruited as subjects and asked to complete a selfadministered questionnaire and consent form. The study was approved by the Ethics Committee of Universiti Teknologi MARA. 


\section{Instruments}

SSB was defined as any beverage with added sugar or calories. This definition covered fruit drinks, milk, carbonated/ soft drinks, coffee/tea and sports and energy drinks.

A self-administered questionnaire that was adapted from a study by Hedrick et al. (2010) was used to obtain data about plain water and SSB consumption pattern. We modified the questionnaire to better reflect local drinking habits in Malaysia, and ran a pilot study to assess the reliability of the modified questionnaire. A Cronbach's alpha of $>0.7$ was obtained for all sections in the questionnaire, which indicated a good reliability. The questionnaire was entirely in English, and definitions or explanations about the food items were also given. The questionnaire consisted of four sections, which included the background participants' (including self-reported weight and height), SSB preferences, frequency of SSB consumption and portion size.

\section{Statistical analysis}

All analyses were performed using the Statistical Package for the Social Sciences (SPSS) version 22. We reported the data descriptively and used the

Table 1. Characteristics and background of the students $(\mathrm{N}=376)$

\begin{tabular}{|c|c|c|}
\hline Characteristic (mean $\pm S D$ ) & Frequency (n) & Percentage (\%) \\
\hline \multicolumn{3}{|l|}{ Age $(22.23 \pm 1.17)$} \\
\hline$\leq 22$ & 260 & 69.1 \\
\hline$>22$ & 116 & 30.9 \\
\hline \multicolumn{3}{|l|}{ Gender } \\
\hline Male & 44 & 11.7 \\
\hline Female & 332 & 88.3 \\
\hline \multicolumn{3}{|l|}{ Faculty } \\
\hline Health science & 188 & 50.0 \\
\hline Non-health science & 188 & 50.0 \\
\hline \multicolumn{3}{|l|}{ Marital status } \\
\hline Single & 374 & 99.5 \\
\hline Married & 2 & 0.5 \\
\hline \multicolumn{3}{|l|}{ Year of Study } \\
\hline $1^{\text {st }}$-year student & 41 & 10.9 \\
\hline $2^{\text {nd }}-$ year student & 125 & 33.2 \\
\hline $3^{\text {rd }}$-year student & 187 & 49.7 \\
\hline Final year student & 23 & 6.1 \\
\hline \multicolumn{3}{|l|}{ Place of living } \\
\hline With family & 23 & 6.1 \\
\hline Hostel resident & 324 & 86.2 \\
\hline Non-resident/rental house & 29 & 7.7 \\
\hline \multicolumn{3}{|l|}{ Body mass index (BMI) } \\
\hline Underweight & 68 & 18.1 \\
\hline Normal & 218 & 58.0 \\
\hline Overweight & 90 & 23.9 \\
\hline \multicolumn{3}{|l|}{ Physical activity } \\
\hline Not exercise & 203 & 54.0 \\
\hline Irregular exercise & 157 & 41.8 \\
\hline Regular exercise & 16 & 4.3 \\
\hline
\end{tabular}


chi-square test to compare between categorical variables. The significance level was defined as $p<0.05$.

\section{RESULTS}

A total of 376 subjects aged 18-30 years participated in this study. There was an equal number of subjects $(n=188)$ from both the health science and non-health sciences faculties. More than half of them had normal BMI (58.0\%) and 54\% of the total did not exercise. The prevalence of overweight among the subjects was high at $23.9 \%$. Table 1 summarises the characteristics and background of our subjects.

Most of the subjects eat outside food $(93.1 \%)$ and did not prepare their food $(92.2 \%)$. They showed a similar preference between buying outside drinks $(74.2 \%)$ and preparing their own drinks (52.4\%) (Table 2).

Table 3 reveals the beverage consumption patterns of the subjects.
Plain water $(92.3 \%)$ was the most commonly consumed beverage. A majority of the subjects drank $>2$ cups each time. This was followed by sweetened coffee or tea (18.4\%) and full cream milk (9.6\%). Besides plain water, most of the subjects consumed only $\leq 1$ cup of the beverage each time. The lowest frequency of intake was alcoholic drinks, with $97.1 \%$ of subjects consuming such beverages either once or not at all in a week. The low intake may have been because of religious reasons since most of the subjects were Muslims who are forbidden from consuming alcohol. Based on Table 3, soft drinks and milk were least favourable among our subjects.

Table 4 summarises the factors related to the consumption of SSB's among the subjects. Approximately two-thirds of the subjects (69.7\%) did not consume SSB on a daily basis. They preferred cold SSB $(66.5 \%)$ purchased from

Table 2. Sources of food and drinks $(\mathrm{N}=376)$

\begin{tabular}{lcc}
\hline Characteristic & Frequency $(n)$ & Percentage (\%) \\
\hline Source of food & & \\
Prepared by family members & 38 & 10.1 \\
$\quad$ Yes & 338 & 89.9 \\
$\quad$ No & & \\
Purchased from the cafeteria/ & 350 & 93.1 \\
restaurant & 26 & 6.9 \\
$\quad$ Yes & & \\
$\quad$ No & 67 & 17.8 \\
Self-prepared & 309 & 82.2 \\
$\quad$ Yes & & \\
$\quad$ No & & \\
Source of drinks & 27 & 7.2 \\
Prepared by family members & 349 & 92.8 \\
$\quad$ Yes & & 74.2 \\
No & 279 & 25.8 \\
Purchased from cafeteria/restaurant & 97 & 52.4 \\
$\quad$ Yes & & 47.6 \\
$\quad$ No & 197 &
\end{tabular}


Table 3. Pattern of consumption of beverages $(\mathrm{N}=376)$

\begin{tabular}{lcccccc}
\hline \multirow{2}{*}{ Types of beverages } & \multicolumn{3}{c}{ 1 time per week } & $\leq 6$ times per week & \multicolumn{3}{c}{ Daily } \\
\cline { 2 - 7 } & $n$ & $\%$ & $n$ & $\%$ & $n$ & $\%$ \\
\hline Plain water & 5 & 1.3 & 24 & 6.4 & 347 & 92.3 \\
100\% fruit juice & 259 & 68.9 & 87 & 23.1 & 30 & 8.0 \\
Sweetened fruit beverages & 247 & 65.7 & 106 & 28.2 & 23 & 6.1 \\
Full cream milk & 252 & 67.0 & 88 & 23.4 & 36 & 9.6 \\
Low fat milk & 276 & 73.4 & 71 & 18.9 & 29 & 7.7 \\
Skimmed milk & 307 & 81.6 & 48 & 12.8 & 21 & 5.6 \\
Regular soft drink & 303 & 80.6 & 56 & 14.9 & 17 & 4.5 \\
Diet soft drink & 335 & 89.1 & 25 & 6.6 & 16 & 4.3 \\
Sweetened coffee or tea & 187 & 49.7 & 120 & 31.9 & 69 & 18.4 \\
Energy or sports drinks & 283 & 75.3 & 74 & 19.7 & 19 & 5.1 \\
Alcoholic drinks & 365 & 97.1 & 7 & 1.9 & 4 & 1.1 \\
Other beverages & 362 & 96.3 & 7 & 1.9 & 7 & 1.9 \\
\hline
\end{tabular}

Table 4. Consumption pattern of sugar-sweetened beverages $(\mathrm{N}=376)$

\begin{tabular}{|c|c|c|}
\hline Parameters & Frequency (n) & Percentage (\%) \\
\hline \multicolumn{3}{|l|}{ Frequency of consumption } \\
\hline Daily & 114 & 30.3 \\
\hline Not daily & 262 & 69.7 \\
\hline \multicolumn{3}{|l|}{ Types of beverages } \\
\hline Hot & 27 & 7.2 \\
\hline Cold & 262 & 69.7 \\
\hline Both & 87 & 23.1 \\
\hline \multicolumn{3}{|l|}{ Location of purchase } \\
\hline Supermarket & 250 & 66.5 \\
\hline Cafeteria & 198 & 52.7 \\
\hline Vending machine & 133 & 35.4 \\
\hline Others & 2 & 0.5 \\
\hline \multicolumn{3}{|l|}{ Location of consumption } \\
\hline Home & 31 & 8.2 \\
\hline Outside & 262 & 69.7 \\
\hline Both & 83 & 22.1 \\
\hline \multicolumn{3}{|l|}{ Time of consume } \\
\hline Breakfast & 74 & 19.7 \\
\hline Lunch & 192 & 51.1 \\
\hline Evening tea & 119 & 31.6 \\
\hline Dinner & 123 & 32.7 \\
\hline \multicolumn{3}{|l|}{ Reason for consume } \\
\hline To reduce thirst & 164 & 43.6 \\
\hline To complement a meal & 123 & 32.7 \\
\hline As a refreshment & 140 & 37.2 \\
\hline To stay up & 117 & 31.1 \\
\hline Others & 14 & 3.7 \\
\hline \multicolumn{3}{|c|}{ Factors influencing to choice of SSB } \\
\hline Taste & 320 & 85.1 \\
\hline Price & 81 & 21.5 \\
\hline Brand & 69 & 18.4 \\
\hline Health concerns & 55 & 14.6 \\
\hline Others & 3 & 0.8 \\
\hline
\end{tabular}


Table 5. Portion size of beverage consumption according to BMI status

\begin{tabular}{|c|c|c|c|c|c|c|c|c|c|}
\hline & \multicolumn{2}{|c|}{$\begin{array}{c}\text { Total } \\
(N=376)\end{array}$} & \multicolumn{2}{|c|}{$\begin{array}{c}\text { Underweight } \\
(n=68)\end{array}$} & \multicolumn{2}{|c|}{$\begin{array}{c}\text { BMI } \\
\text { Normal } \\
(n=218)\end{array}$} & \multicolumn{2}{|c|}{$\begin{array}{c}\text { Overweight } \\
(n=90)\end{array}$} & \multirow[t]{2}{*}{ p-value ${ }^{\dagger}$} \\
\hline & $n$ & $\%$ & $n$ & $\%$ & $n$ & $\%$ & $n$ & $\%$ & \\
\hline \multicolumn{10}{|l|}{ Plain Water } \\
\hline$\leq 1$ cup each time & 49 & 13.0 & 19 & 27.9 & 26 & 11.9 & 4 & 4.4 & \multirow{3}{*}{$0.000^{*}$} \\
\hline$\leq 2$ cups each time & 70 & 18.6 & 10 & 14.7 & 45 & 20.6 & 15 & 16.7 & \\
\hline$>2$ cups each time & 257 & 68.4 & 39 & 57.4 & 147 & 67.4 & 71 & 78.9 & \\
\hline \multicolumn{10}{|l|}{$100 \%$ fruit juice } \\
\hline$\leq 1$ cup each time & 291 & 77.4 & 55 & 80.9 & 172 & 78.9 & 64 & 71.1 & \multirow{3}{*}{0.319} \\
\hline$\leq 2$ cups each time & 75 & 19.9 & 10 & 14.7 & 41 & 18.8 & 24 & 26.7 & \\
\hline$>2$ cups each time & 10 & 2.7 & 3 & 4.4 & 5 & 2.3 & 2 & 2.2 & \\
\hline \multicolumn{10}{|c|}{ Sweetened fruit beverages } \\
\hline$\leq 1$ cup each time & 280 & 74.5 & 50 & 73.5 & 164 & 75.2 & 66 & 73.3 & \multirow{3}{*}{0.809} \\
\hline$\leq 2$ cups each time & 87 & 23.1 & 15 & 22.1 & 50 & 22.9 & 22 & 24.4 & \\
\hline$>2$ cups each time & 9 & 2.4 & 3 & 4.4 & 4 & 1.8 & 2 & 2.2 & \\
\hline \multicolumn{10}{|l|}{ Full cream milk } \\
\hline$\leq 1$ cup each time & 300 & 79.8 & 54 & 79.4 & 178 & 81.7 & 68 & 75.6 & \multirow{3}{*}{0.572} \\
\hline$\leq 2$ cups each time & 72 & 19.1 & 13 & 19.1 & 39 & 17.9 & 20 & 22.2 & \\
\hline$>2$ cups each time & 4 & 1.1 & 1 & 1.5 & 1 & 0.5 & 2 & 2.2 & \\
\hline \multicolumn{10}{|l|}{ Low fat milk } \\
\hline$\leq 1$ cup each time & 312 & 83.0 & 57 & 83.8 & 182 & 83.5 & 73 & 81.1 & \multirow{3}{*}{0.815} \\
\hline$\leq 2$ cups each time & 58 & 15.4 & 9 & 13.2 & 33 & 15.1 & 16 & 17.8 & \\
\hline$>2$ cups each time & 6 & 1.6 & 2 & 2.9 & 3 & 1.4 & 1 & 1.1 & \\
\hline \multicolumn{10}{|l|}{ Skimmed milk } \\
\hline$\leq 1$ cup each time & 336 & 89.4 & 63 & 92.6 & 194 & 89.0 & 79 & 87.8 & \multirow{3}{*}{0.650} \\
\hline$\leq 2$ cups each time & 38 & 10.1 & 5 & 7.4 & 22 & 10.1 & 11 & 12.2 & \\
\hline$>2$ cups each time & 2 & 0.5 & 0 & 0.0 & 2 & 0.9 & 0 & 0.0 & \\
\hline \multicolumn{10}{|l|}{ Regular soft drink } \\
\hline$\leq 1$ cup each time & 304 & 80.9 & 55 & 80.9 & 183 & 83.9 & 66 & 73.3 & \multirow{3}{*}{0.103} \\
\hline$\leq 2$ cups each time & 62 & 16.5 & 13 & 19.1 & 28 & 12.8 & 21 & 23.3 & \\
\hline$>2$ cups each time & 10 & 2.7 & 0 & 0.0 & 7 & 3.2 & 3 & 3.3 & \\
\hline Diet soft drink & & & & & & & & & \\
\hline$\leq 1$ cup each time & 337 & 89.6 & 62 & 91.2 & 198 & 90.8 & 77 & 85.6 & \\
\hline$\leq 2$ cups each time & 36 & 9.6 & 6 & 8.8 & 18 & 8.3 & 12 & 13.3 & 0.614 \\
\hline$>2$ cups each time & 3 & 0.8 & 0 & 0.0 & 2 & 0.9 & 1 & 1.1 & \\
\hline Sweetened coffee or & & & & & & & & & \\
\hline$\leq 1$ cup each time & 252 & 67.0 & 51 & 75.0 & 140 & 64.2 & 61 & 67.8 & \\
\hline$\leq 2$ cups each time & 103 & 27.4 & 15 & 22.1 & 65 & 29.8 & 23 & 25.6 & 0.511 \\
\hline$>2$ cups each time & 21 & 5.6 & 2 & 2.9 & 13 & 6.0 & 6 & 6.7 & \\
\hline Energy or sports drir & & & & & & & & & \\
\hline$\leq 1$ cup each time & 278 & 73.9 & 51 & 75.0 & 164 & 75.2 & 63 & 70.0 & \\
\hline$\leq 2$ cups each time & 87 & 23.1 & 17 & 25.0 & 48 & 22.0 & 22 & 24.4 & 0.322 \\
\hline$>2$ cups each time & 11 & 2.9 & 0 & 0.0 & 6 & 2.8 & 5 & 5.6 & \\
\hline Alcoholic beverages & & & & & & & & & \\
\hline$\leq 1$ cup each time & 367 & 97.6 & 67 & 98.5 & 213 & 97.7 & 87 & 96.7 & \\
\hline$\leq 2$ cups each time & 9 & 2.4 & 1 & 1.5 & 5 & 2.3 & 3 & 3.3 & 0.742 \\
\hline$>2$ cups each time & 0 & 0.0 & 0 & 0.0 & 0 & 0.0 & 0 & 0.0 & \\
\hline Others & & & & & & & & & \\
\hline$\leq 1$ cup each time & 373 & 99.2 & 67 & 98.5 & 217 & 99.5 & 89 & 98.9 & \\
\hline$\leq 2$ cups each time & 3 & 0.8 & 1 & 1.5 & 1 & 0.5 & 1 & 1.1 & 0.665 \\
\hline$>2$ cups each time & 0 & 0.0 & 0 & 0.0 & 0 & 0.0 & 0 & 0.0 & \\
\hline
\end{tabular}

${ }^{\dagger}$ Analysis using $x^{2}$ test ${ }^{*} p<0.05$ 
supermarkets (66.5\%), and they typically consumed these when away from home or in their rooms $(69.7 \%)$. The preferred time for SSB consumption was during lunch $(51.1 \%)$, in order to reduce thirst $(43.6 \%)$, as that was the prime time for hot weather. SSBs were predominantly chosen based on taste (85.1\%).

Further analyses on the association between beverage consumption and BMI showed significant differences between plain water consumption portion size and BMI $(p<0.05)$ (Table 5). Those who were overweight consumed a significantly higher amount ( $>2$ cups) of plain water each time $(78.9 \%)$ compared to those who were underweight $(27.9 \%)$, who typically drank $<1$ cup of water each time.

\section{DISCUSSION}

This study evaluated plain water and SSB consumption patterns among undergraduates from a Malaysian university. Vella-Zarb \& Elgar (2009) have reported that college and university students were susceptible to unhealthy weight-related behaviours including consumption of SSB. Various studies in multiple countries have shown that the trend of increasing SSB intake among university students is worrying (Vilaro et al., 2018; Joh, Lim \& Cho, 2015). Highly urbanised countries such as the United States and Australia have reported high intakes of sweetened beverages, at 40$50 \%$ of university students who were studied (O'Leary et al., 2012; Block et al., 2013). Similar trends have also been reported among Turkish university students (Deliens et al., 2015). Thus, the trend affects the students' intake on plain water. Presently, studies on sugary beverages and plain water consumption within Malaysia remain scarce.

Most of the students consumed foods and drinks from outside their homes. The result is to be expected, as most of the subjects lived on campus, with limited access to food preparation facilities. As discussed by in a previous study (Greaney et al., 2009), food choices of students were influenced by the availability and accessibility of foods and cooking facilities. It has also been shown that such living arrangements, particularly when living outside of their family home, are associated with unhealthy dietary habits, including increased SSB consumption (An, 2016). In line with one study (Vilaro et al., 2018), our subjects also reported taste as one of the determinants in choosing type of SSB. Taste is an important reason for high SSB consumption and unhealthy diets.

Caffeinated drinks and sweetened fruit beverages (including cordial drink) were the most consumed SSBs among our subjects. This is in line with a study by Norimah et al. (2008) which reported a high consumption of coffee and tea among Malaysians. In Malaysia, such beverages are often prepared with added sugar and condensed milk, which eventually contributes to high fat and calorie. Our study found that although most of the subjects did not consume SSB on a daily basis, almost $70 \%$ consumed SSBs multiple times in a week. Again, this may be related to the high frequency $(74.2 \%)$ of students who bought their drinks from outside at cafeteria/restaurants. As reported by previous study, eating/drinking out was the largest contributor to SSBs intake (An, 2016). Frequent SSB consumption is associated with an increased risk of obesity and related non-communicable diseases (NCDs). There have been many reports over this decade of the early onset of NCDs among Asians (Dans et al., 2011; Misra \& Khurana, 2011). Thus, strategies to prevent the onset of NCDs must start earlier as a healthy lifestyle during childhood and youth can prevent the onset of NCDs later in adulthood. 
This study revealed that overweight students were highly cautious of their dietary intake, particularly of SSBs. They drank significantly more plain water compared to the underweight subjects. This is consistent with previous study, which reported that overweight and obese young adults were found to be high water consumers (Lee, Park \& Kim, 2014). Obese persons attempt to reduce their energy intake by substituting plain water for SSBs (Park et al. 2012). In contrast, there were fewer underweight subjects who did not take plain water at all on a daily basis. This is unfortunate, as having normal or underweight BMI should not be taken to mean that healthy eating is to be ignored. A randomised controlled trial among 646 children reported that the reduction of sweets and sweetened beverages observed in the intervention group significantly reduced their BMI and blood pressure (Chan \& Woo, 2010). Another recent study conducted in Japan on water intake revealed that there was an inverse correlation between high water intake and risk of cardiovascular diseases (Cui et al., 2018). Therefore, a high intake of water particularly plain water must be promoted seriously in our community lifestyle. In Malaysia, the consumption of $1 \mathrm{ml}$ of water for each calorie eaten is recommended (NCCFN, 2010). This amount is equivalent to 7 to 11 glasses of water or fluid per day.

Another result that is of concern in this study is the very low intake of milk. Fewer than $10 \%$ of our subjects drank milk on a daily basis. The revelation is in agreement with studies by Norimah et al. (2008) \& Talaei et al. (2018), who also reported a low level of milk intake among the Malaysian and Asian populations. As milk is the primary source of calcium, it is critical to ensure that the recommended level of daily calcium intake is fulfilled. However, previous study have shown that calcium intake among Malaysians is low and does not meet recommended nutrient intake (RNI) (Alam, 2012). Low calcium and vitamin intake, together with a sedentary lifestyle, are risk factors for osteoporosis. Therefore, an innovative approach should be made to promote proper nutrition and physical activity for healthy bones among young adults.

Many studies have compared dietary intake of SSBs with gender (Grimes et al., 2013; Ha et al., 2016; Ranjit et al., 2010). However, our study did not find any gender differences in SSB consumption.

An important limitation of this study was the preponderance of females over males. More than $80 \%$ of the subjects were female. In general, females are more concerned about their calorie intake. This may explain the low intake of daily SSBs among them. Another limitation was that we did not take into account the food intake habits by way of daily total calorie intake of the subjects.

\section{CONCLUSION}

Understanding trends in plain water and SSB consumption, together with healthy and balanced dietary intake among young adults is imperative to formulate effective nutritional intervention strategies to achieve a healthy lifestyle. Ultimately, this may help to prevent the risk of obesity and related diseases later in life. The present study highlights that lowering SSB intake and increasing plain water intake, especially among the underweight, is crucial. The results from this study may help by providing information for future intervention studies. In addition to SSB, future interventions should also focus on a strategy to increase calcium intake among young adults. 


\section{Acknowledgement}

We would like to thank Universiti Teknologi MARA for grant number 600-IRMI/DANA 5/3/LESTARI (0100/2016) and for its support throughout this study.

\section{Authors' contributions}

TNIMF, principal investigator, conceptualised and designed the study, prepared the draft of the manuscript and reviewed the manuscript; NJN, assisted in design the study, assisted in drafting the manuscript, reviewed the manuscript; ASM conducted the study, data analysis and interpretation, and prepared the draft of the manuscript.

\section{Conflict of interest}

There is no conflict of interest to declare.

\section{References}

Alam P (2012). Nutritional status and eating practices among university students in selected universities in Selangor, Malaysia. Asian J Clin Nutr 4(3):77-87.

Amarra MS, Khor GL \& Chan P (2016). Intake of added sugar in Malaysia: a review. Asia Pac J Clin Nutr 25(2): 227-240. doi:10.6133/ apjen.2016.25.2.13.

An R (2016). Fast-food and full-service restaurant consumption and daily energy and nutrient intakes in US adults. European $\mathrm{J}$ Clin Nutr $70(1): 97$.

Block JP, Gillman MW, Linakis SK \& Goldman RE (2013). "If it tastes good, I'm drinking it": qualitative study of beverage consumption among college students. $J$ Adolescent Hlth 52(6):702-6.

Chan RSM \& Woo J (2010). Prevention of overweight and obesity: how effective is the current public health approach. Int $J$ Environ Res Publ Hlth $7(3): 765-783$.

Cheah YK, Abdul Adzis A, Abu Bakar J \& Applanaidu SD (2018). Factors associated with consumption of sugar-sweetened foods and beverages in Malaysia: an ethnic comparison. Int $J$ Diab in Dev Countries 39 (3):568-578 doi:10.1007/s13410-018-0673-7.

Cui R, Iso H, Eshak ES, Maruyama K \& Tamakoshi A (2018). Water intake from foods and beverages and risk of mortality from CVD: the Japan Collaborative Cohort (JACC) Study. Publ Hlth Nutr 21(16):3011-3017. doi:10.1017/ S1368980018001386.
Dans A, Ng N, Varghese C, Tai ES, Firestone R \& Bonita R (2011). The rise of chronic noncommunicable diseases in southeast Asia: time for action. The Lancet 377(9766):680-689.

Dehghan M, Mente A, Zhang X, Swaminathan S, Li W, Mohan V, Iqbal R, Kumar R, Wentzel-Viljoen E \& Rosengren A (2017). Associations of fats and carbohydrate intake with cardiovascular disease and mortality in 18 countries from five continents (PURE): a prospective cohort study. The Lancet 390(10107):2050-2062.

Deliens T, Clarys P, De Bourdeaudhuij I \& Deforche B (2015). Correlates of university students' soft and energy drink consumption according to gender and residency. Nutrients 7(8):6550-66.

Greaney ML, Less FD, White AA, Dayton SF, Riebe D, Blissmer B, Shoff S, Walsh JR \& Greene GW (2009). College students' barriers and enablers for healthful weight management: a qualitative study. J Nutr Edu and Behav 41(4):281-6.

Grimes CA, Riddell LJ, Campbell KJ \& Nowson CA (2013). Dietary salt intake, sugar-sweetened beverage consumption, and obesity risk. Pediatrics 131(1):14-21.

Ha K, Chung S, Lee HS, Kim CI, Joung H, Paik HY \& Song Y (2016). Association of dietary sugars and sugar-sweetened beverage intake with obesity in Korean children and adolescents. Nutrients 8(1):31.

Hedrick VE, Comber DL, Estabrooks PA, Savla J \& Davy BM (2010). The beverage intake questionnaire: determining initial validity and reliability. J Am Dietetic Assoc 110(8):12271232.

Heitmann BL, Westerterp KR, Loos RJF, Sørensen TIA, O'Dea K, McLean P, Jensen TK, Eisenmann J, Speakman JR, Simpson SJ, Reed DR \& Westerterp-Plantenga MS (2012). Obesity: lessons from evolution and the environment. Obesity Rev 13:910-922.

Hu FB \& Malik VS (2010). Sugar-sweetened beverages and risk of obesity and type 2 diabetes: epidemiologic evidence. Physiol Behav 100(1):47-54.

Joh HK, Lim CS \& Cho B (2015). Lifestyle and dietary factors associated with serum 25-hydroxyvitamin D Levels in Korean young adults. J Korean Med Sci 30(8):1110-1120.

Lee HS, Park S \& Kim MH (2014). Factors associated with low water intake among South Korean adolescents-Korea National Health and Nutrition Examination Survey, 2007-2010. Nutri Res and Pract 8(1):74-80. 
Misra A \& Khurana L (2011). Obesity-related noncommunicable diseases: South Asians vs White Caucasians. Int J Obesity 35(2):167.

Muckelbauer R, Sarganas G, Grüneis A \& MüllerNordhorn J (2013). Association between water consumption and body weight outcomes: a systematic review. Am J Clin Nutr 98(2):282299.

NCCFN (2010). Malaysian Dietary Guidelines. National Coordinating Committee on Food and Nutrition, Ministry of Health Malaysia, Putrajaya.

Ng M, Fleming T, Robinson M, Thomson B, Graetz N, Margono C,...Gakidou E (2014). Global, regional, and national prevalence of overweight and obesity in children and adults during 1980-2013: a systematic analysis for the Global Burden of Disease Study 2013. The Lancet 384(9945): 766-781. https://doi. org/10.1016/S0140-6736(14)60460-8.

Norimah AK, Safiah M, Jamal K, Haslinda S, Zuhaida H, Rohida S, Fatimah S, Norazlin S, Poh BK, Kandiah M, Zalilah MS, Wan Manan WM, Fatimah S \& Azmi MY (2008). Food consumption patterns: findings from the Malaysian Adult Nutrition Survey (MANS). Mal J Nutr 14(1): 25-39.

O'leary F, Hattersley L, Lesley KI \& AllmanFarinelli M (2012). Sugary drink consumption behaviours among young adults at university. Nutr \& Dietetics 69(2):119-23.
Park S, Blanck HM, Sherry B, Brener N \& O’Toole $\mathrm{T}$ (2012). Factors associated with low water intake among US high school studentsNational Youth Physical Activity and Nutrition Study, 2010. J Acad of Nutr and Dietetics 112(9):1421-7.

Ranjit N, Evans MH, Byrd-Williams C, Evans AE \& Hoelscher DM (2010). Dietary and activity correlates of sugar-sweetened beverage consumption among adolescents. Pediatrics 126(4):e754-e761.

Talaeia M, Pan A, Yuan J \& Koh W (2018). Dairy intake and risk of type 2 diabetes. Clin Nutr 37(2):712-718.

Vella-Zarb RA \& Elgar FJ (2009). The "freshman 5": A meta-analysis of weight gain in the freshman year of college. J Am Coll Health 58:161-166. doi: 10.1080/07448480903221392.

Vilaro MJ, Colby SE, Riggsbee K, Zhou W, ByrdBredbenner C, Olfert MD, Barnett TE, Horacek T, Sowers M \& Mathews AE (2018). Food choice priorities change over time and predict dietary intake at the end of the first year of college among students in the US. Nutrients 10(9):1296. 